AC 2009-1546: A REFUTATION OF THE PERCENTAGES OFTEN ASSOCIATED WITH EDGAR DALE'S "CONE OF LEARNING"

James Stice, University of Texas, Austin 


\section{A Refutation of the Percentages Often Associated with Edgar Dale's "Cone of Learning"}

In a 1987 article on using the Kolb cycle to improve student learning, I mentioned Edgar Dale's “Cone of Learning," which has resulted lately in a lot of requests for more information on the source of the data supporting his intuitive model.

Recent attempts to obtain the source of the numbers attached to Dale's model indicate that the Numbers (which were not provided by Dale) are fraudulent.

This paper attempts to shed light on this rather widespread "myth" of student learning.

An article I wrote titled, “Using Kolb's Learning Cycle to Improve Student Learning," appeared in the February 1987 issue of Engineering Education ${ }^{1}$. In that article I discussed the use of David Kolb's Learning Styles Inventory in designing engineering coursework. While not related to the main message of the paper, I mentioned retention of learned material by a learner, and presented the following table of data:

Learning Method

What they read

What they hear

What they see

What they see and hear

What they say

What they say as they do something
Retention by Learner

$10 \%$

26

30

50

70

90

I obtained these data as a handout at a "Train the Trainer" workshop held at the University of Wisconsin-Eau Claire in 1970. The source was listed as "Socony-Vacuum Oil Company," which told me that the date was in the 1930s or 1940s. I wrote that "these numbers are nearly identical to numbers attributed to Edgar Dale's Cone of Learning...", one version of which is shown below ${ }^{2}$.

The percentages given in this figure seemed reasonable to me at the time I saw them, and I have distributed the above diagram at a couple of hundred workshops I have given since the 1970s. In the past two or three years, however, I have received a flood of requests for the source of those data. I launched a serious effort to track them down, without success; most others who have written on this subject cite the same Dale reference I have given above. None described the research that yielded these data, however.

Then I received an e-mail from a man who referred me to an essay by Will Thalheimer. Dr. Thalheimer is President of Work-Training Research, Inc., of Somerville, Massachusetts, and he has published the results of his research about how Dale's Cone developed and was disseminated ${ }^{3}$. 


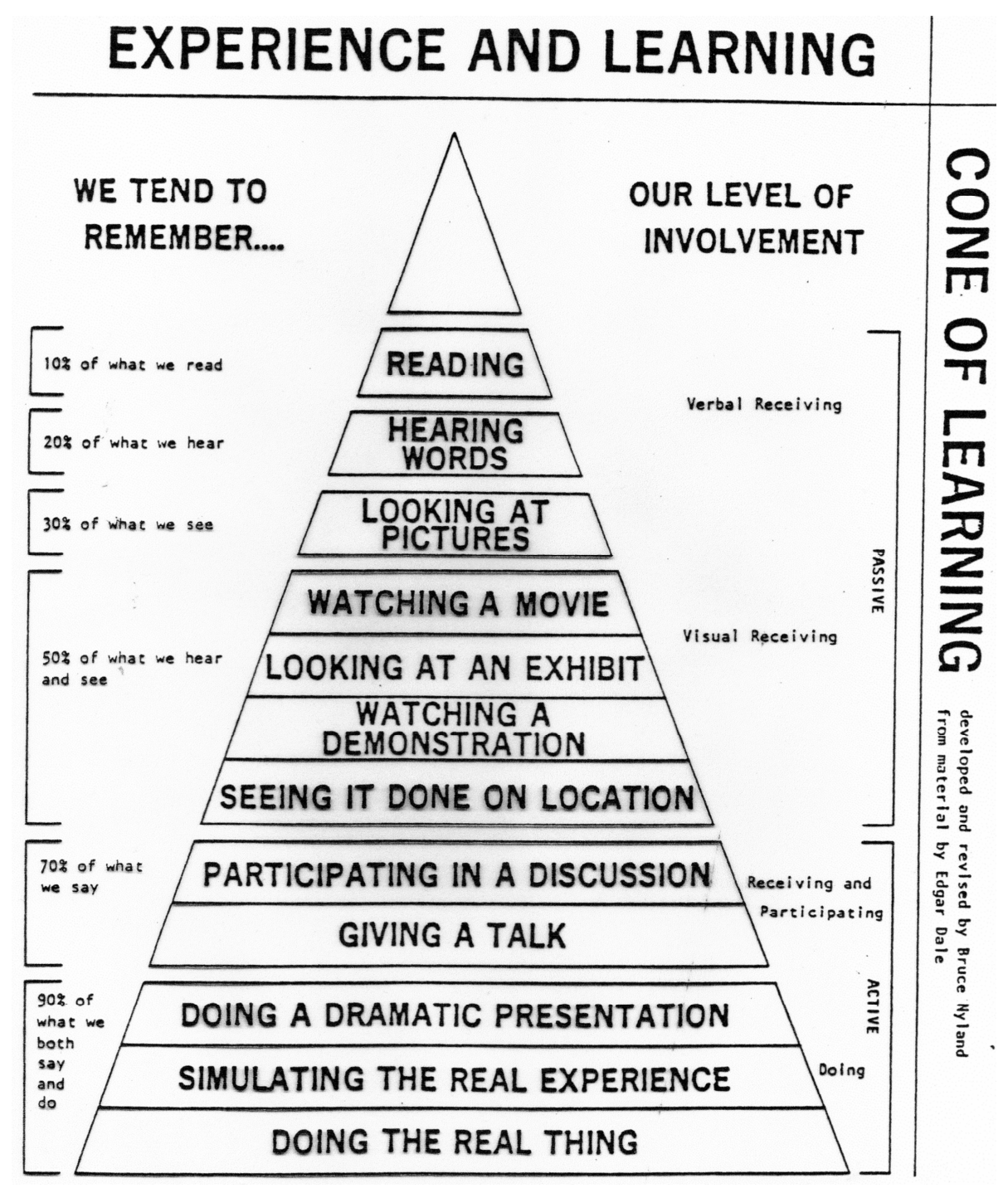

Thalheimer reports that what Edgar Dale called his "Cone of Experience" was developed in 1946. He developed it to rank-order the efficacy of various audio-visual media. It was intuitive only - he didn't provide any numbers and there is no record that he did any research to produce the model. Dale's Cone is shown in the third edition of his book, without numbers ${ }^{4}$.

Thalheimer further reports that Michael Molenda, a professor at Indiana University, suggests that the numbers may have come from Lt. Colonel Paul John Phillips, who developed training materials for the Army Ordnance School at Aberdeen Proving Grounds in Maryland during World War II, and the numbers may have been developed there. He also developed training materials for the petroleum industry at the University of Texas (Austin), both before and after the war. I haven't found anyone at the University of Texas who remembers this man.

The numerical percentages first appeared in an article by D. G. Treichler, an employee of Mobil Oil Company in $1967^{6}$. He didn't cite any research. At some time someone conflated Edgar's Cone and Treichler's dubious percentages. Since then the Cone and the percentages have been referred to together and many people have accepted them uncritically. In Thalheimer's words, 
the percentages are "bogus," and the coupling of those numbers with Dale's Cone are "fraudulent."

Thalheimer feels that, while many of the people who used this information and passed it on to others are reputable, some of the people who fabricated the data intended the deception. He also feels the numbers are dangerous. He exhorts us all to do our research carefully, publish the results, and take responsibility for the information we transmit in order that all can trust it. Mea culpa. I made a cursory attempt to corroborate the numbers I included in my paper (which weren't really important to the subject of the article), but didn't find them anywhere. I have come to regret having mentioned the numbers at all!

I am disappointed, but not outraged, that the numbers are bogus. I had some reservations when I first saw them, because I don't learn as much from hearing as I do from reading, for instance, and this is backward from what Dale's Cone suggests. I'm not "ear-minded" as the learning psychologists say, and I understand that about a third of the U. S. population is like me (and I can't quote an exact source for this number either - I got it from learning psychologist Fred Keller $^{7}$ in a conversation with him). I don't receive vocal information as efficiently as I do when I read about something - I can always read text over again, but it isn't usually possible to "replay" a lecture or a conversation. So my learning skills don't match the lower levels of Dale's Cone. But after 43 years of teaching engineering subjects I am quite comfortable with the ideas that, for most engineering students, Visual Receiving is superior to Verbal Receiving, taking notes is far less useful than discussing issues (which requires participation), and active learning is superior to passive learning (think TAPPS, Thinking Aloud Pairs Problem Solving; ProblemBased Learning; group work; co-operative learning, etc.). So the Dale Cone is a useful intuitive concept, and can help us analyze and design learning experiences for our students, and not just from the standpoint of audio-visual media. The numbers really aren't that important - the useful idea is that the method used in presenting material makes a difference to the learner. Another useful idea is that learners learn in idiosyncratic ways (the point of my original article). We need to keep both these ideas in mind when we design instruction.

As an aside, I was curious about the Socony-Vacuum Oil Company source for the data given at the beginning of this article, and also about D. G. Treichler. I have looked into the history of the company, and can report its gradual evolution to the present day ${ }^{8,9}$.

Standard Oil Company of New York (Socony) acquired all the assets of Vacuum Oil Company in 1931. Their gasoline brand was named "Mobilgas." In 1934 the name was changed to Socony-Vacuum Oil Company, Inc. In 1955 the name was changed to Socony Mobil Oil Company, and in 1966 the company dropped the Socony name and became Mobil Oil Company.

Another of the Standard Oil Companies, Standard Oil Company of New Jersey (Jersey Standard), began to market gasoline under the name "Esso." In offshore markets, this trade name had some unfortunate connotations - one translation was "stalled car." After a serious search to find a name that was unique and had no adverse meanings, Jersey Standard changed its name to "Exxon."

In 1999, Exxon and Mobil Oil Company merged, and became ExxonMobil.

So my estimate, that the approximate date of the Soicony-Vacuum Oil Company numbers was in the 1930s or 1940s, was in the ballpark. Also, Treichler's article appeared in 1967, after Socony-Vacuum had changed its name to Mobil Oil Company. The names of the companies 
associated with the purported percentages connected with Dale's "Cone" are consistent with the dates given.

I am guilty of sloppy thinking and writing when I penned that 21-year-old article, because I had accepted the Dale-Treichler combination uncritically. It is particularly galling that including my reference to it really didn't have much to do with the major thrust of the piece. It has resulted in a real learning experience for me, however. I regret that I have inadvertently contributed to the dissemination of the unsubstantiated numbers connected with Dale's Cone, and I have written this article to apologize for my transgression, and to implore my colleagues to subject their writings to merciless scrutiny for good research, accuracy, and complete literary citations.

Mark Twain said that a lie can travel half way around the world while the truth is putting on its shoes. Well, my shoes are laced up, and I'm trying to atone for my sins!

Bibliographic Information

1. (Removed from draft for author anonymity.)

2. Handout from "Training the Trainer" workshop, University of Wisconsin-Eau Claire, 1970. Author unknown.

3. Thalheimer, Will, "People Remember 10\%, 20\% ... Oh, Really?” Work-Learning Research, Inc. (May 1, 2006). Available at http://www.work-learning/chigraph.htm.

4. Dale, E., Audio-visual Methods in Teaching, p. 107. New York: Dryden (1969).

5. Molenda, M. H., personal communications with Will Thalheimer, February and March, 2003.

6. Treichler, D. G., "Are You Missing the Boat in Training Aids?" Film and Audio-Visual Communication, 1, 14-16, 28-30, 48 (1967).

7. Keller, F. S., personal conversation, 1973.

8. Eric V. Thompson, "A Brief History of Major Oil Companies in the Gulf Region," Petroleum Archives Project, Arabian Peninsula and Gulf Studies Program (APAG), University of Virginia (no date). Available at http://www.virginia.edu/lgpr/APAG/apagoilhistory.html.

9. Robert V. Droz, "Standard Oil: 1961," July 12, 2001. Available at http://www.ushighways.com/sohist1961/htm 